\title{
Photosynthetic Surges in Coffee Seedlings
}

\author{
John P. Decker ${ }^{1}$ and Marco A. Tión
}

\section{INTRODUCTION}

An apparatus $(1)^{3}$ was developed for use in studies of the effects of environmental factors on photosynthetic yields from coffee (Coffea arabica) seedlings. The present study was undertaken as a functional test of a prototype of the apparatus. Earlier studies on the photosynthesis of coffee trees were made by Nutman $(3,4)$.

An illuminated green leaf absorbs $\mathrm{CO}_{2}$ from the surrounding air (apparent photosynthesis); in darkness it exhales or exudes $\mathrm{CO}_{2}$ (respiration). Decker and Wien (2) have reported that when eucalyptus leaves were alternately illuminated and darkened, initial rates of intake and evolution were momentarily high. In the study reported here similar but more distinct insurges and outsurges were observed with leaves of Coffea arabica.

\section{MATERIALS AND METHODS}

The coffee plants used were seedlings about $50 \mathrm{~cm}$. high that had grown in 10-inch pots in a greenhouse.

$\mathrm{CO}_{2}$ intake and evolution were measured as changes of $\mathrm{CO}_{2}$ concentration of a fixed volume of air surrounding a single leaf. The apparatus has been described elsewhere in detail (1). It consisted of a leaf chamber, an airpump, and an infrared gas analyzer-Liston-Becker model $15 \mathrm{~A}$ coupled to a recording milliammeter-connected in closed series with metal and plastic tubing. An intact leaf, still attached to a plant, was sealed in the chamber with modeling clay. It was left for $15-20$ minutes under 3,000 f.c. of illumination and with laboratory air passing through the chamber at about $1,000 \mathrm{ml}$. per minute. Then $\mathrm{CO}_{2}$ was added to bring the concentration up to about 500 p.p.m.; the system was closed and recordings were made of the time-course of $\mathrm{CO}_{2}$ concentration through repeated lightdark-light cycles and other treatments.

\section{EXPERIMENTS AND RESULTS}

Figure 1 shows a typically smooth time-course of $\mathrm{CO}_{2}$ concentration with a leaf under continuous illumination. Slope of the curve at any point

1 Plant Physiologist, Rocky Mountain Forest and Range Experiment Station, Forest Service, U.S. Department of Agriculture; headquarters at Colorado State University, Fort Collins, Colo.; author stationed at Arizona State College, Tempe, Ariz.

${ }^{2}$ Associate Plant Physiologist, Agricultural Experiment Station, University of Puerto Rico, Río Piedras, P.R.

${ }^{3}$ Italic numbers in parentheses refer to Literature Cited p. 56. 
represents rate of $\mathrm{CO}_{2}$ intake by the leaf, or apparent photosynthesis. The uniform change of slope indicates that apparent photosynthesis decelerated uniformly with decreasing $\mathrm{CO}_{2}$ concentration. A steady state

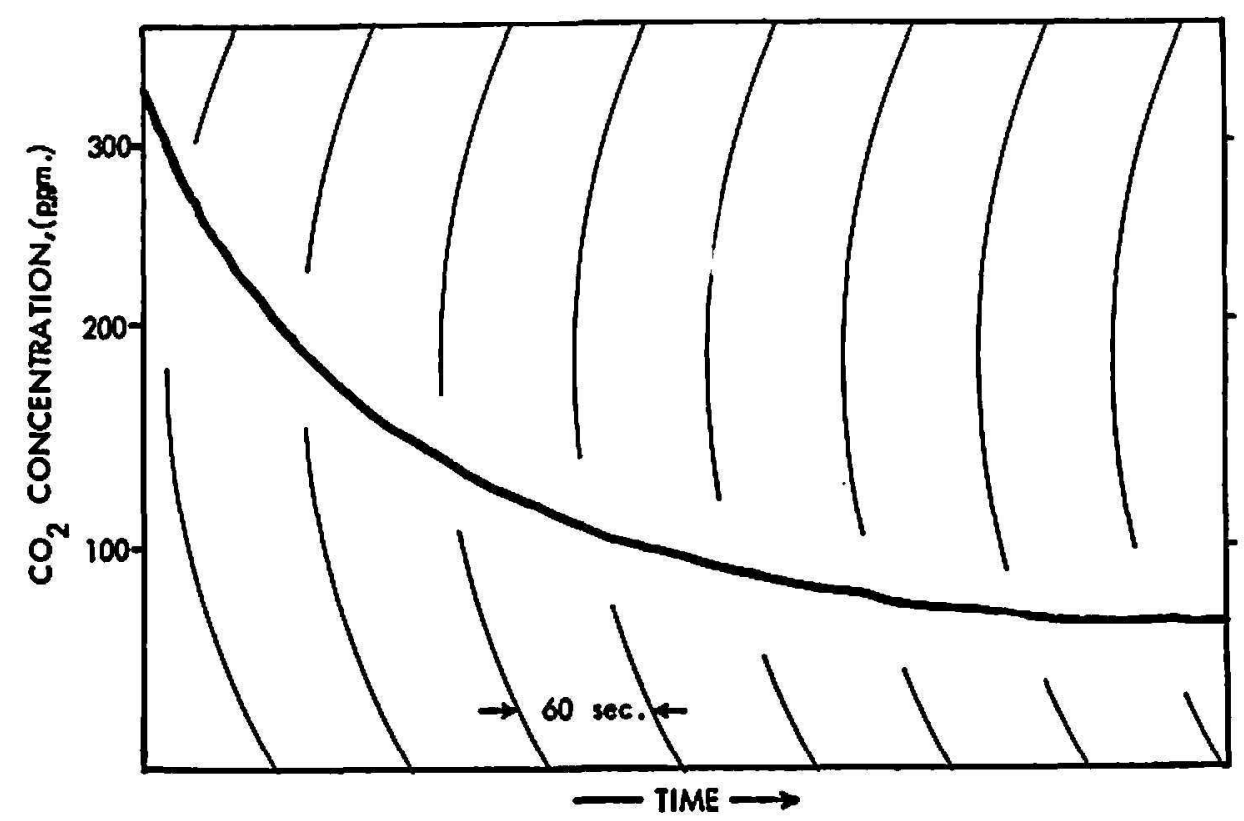

Fra. 1.-Section of milliammeter chart showing time-course of $\mathrm{CO}_{2}$ concentration of air enclosed with an intact leaf of coffee illuminated at 3,000 f.c. Air temperature $32^{\circ} \mathrm{C}$.

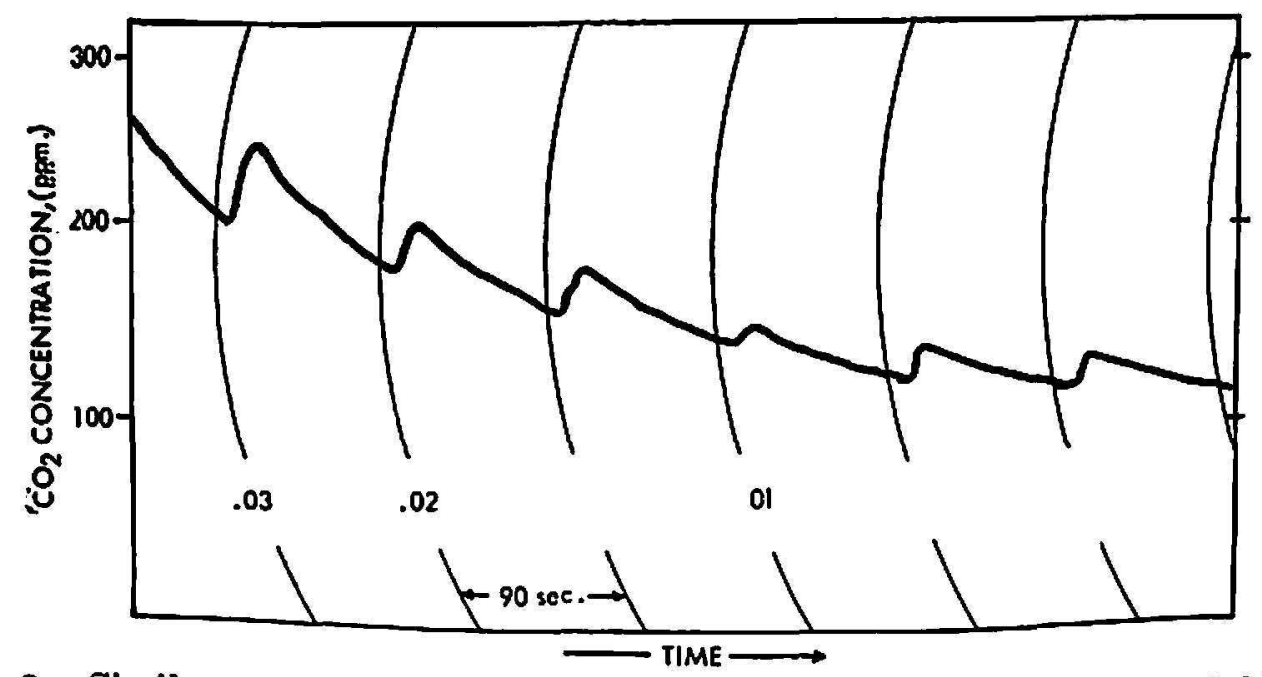

Fig. 2.-Similar to fig. 1, but showing effect of injection of $0.03,0.02$, or $0.01 \mathrm{ml}$. of $\mathrm{CO}_{2}$ into leaf chamber. Injections were made at times indicated; those not labeled are $0.02 \mathrm{ml}$.

was finally reached when photosynthesis had diminished until it just equalled respiration, and apparent photosynthesis became zero.

Figure 2 is similar to figure 1, except that it shows the effect of small bursts of $\mathrm{CO}_{2}$ introduced directly into the leaf chamber by means of a 
micropipette. Note that the system surged smoothly to a new higher concentration with only a slight suggestion of overshoot and subsequent oscillation. The delay of about 10 seconds between the introduction of $\mathrm{CO}_{2}$ and the beginning of the upward swerve indicates the time required for the pump to transfer air from chamber to analyzer.

Figure 3 is similar to figure 1, except that it shows the time course of $\mathrm{CO}_{2}$ concentration during alternate periods of light and darkness. A section of this tracing representing one complete light-dark-light cycle is
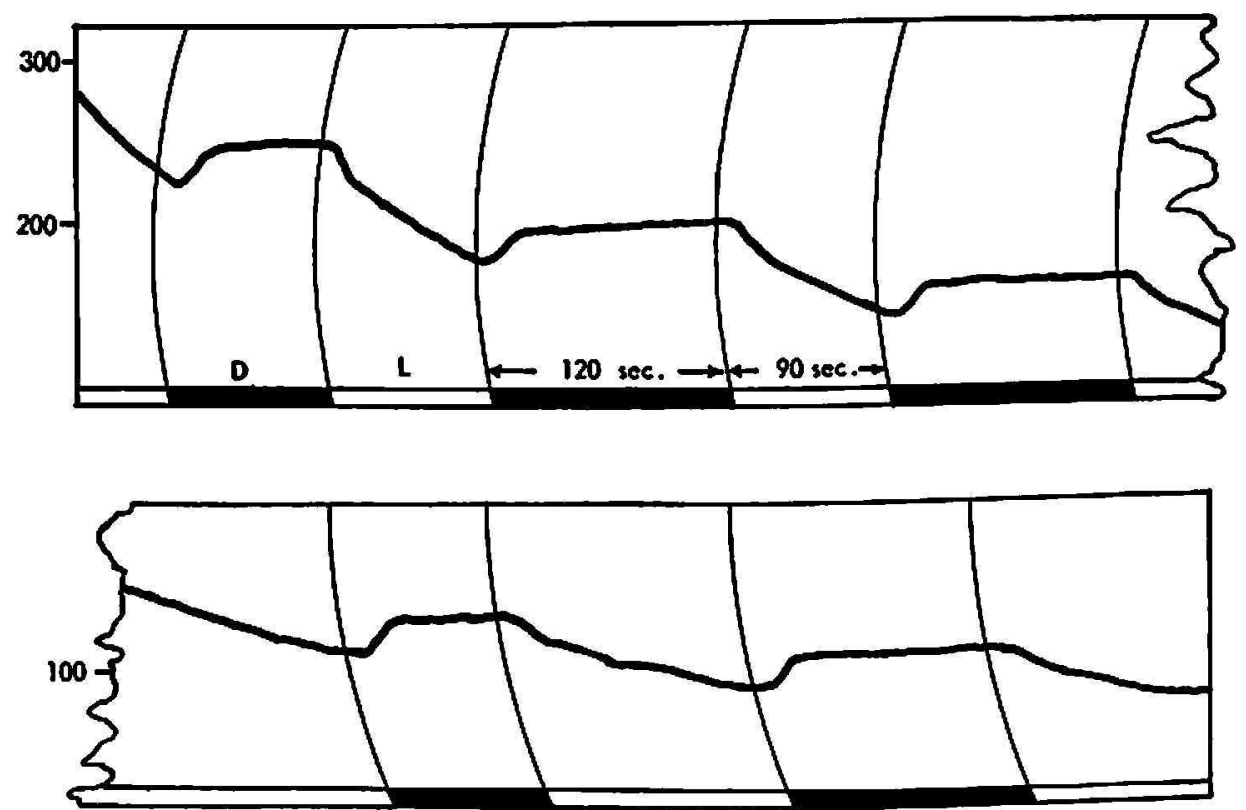

Fig. 3.-Similar to fig. 1, but showing the effect of alternate periods of light and darkness. The two sections of the chart represent one continuous record, with the right end of the upper section fitting the left end of the lower section with an offset such that the recorder-pen tracing is continuous. Periods of darkness are indicated by the black bands along the lower edge of each segment.

enlarged in figure 4 . The slope of segment $a b$ indicates the rate of apparent photosynthesis. The chamber was darkened as time-marker indicated. The delay of about 10 seconds between darkening and the first upward swerving of the tracing is about equal to the delay when $\mathrm{CO}_{2}$ was introduced mechanically (fig. 2). Slope of segment $b c$ indicates the initial rate of $\mathrm{CO}_{2}$ evolution immediately following darkening. The slope of segment $c e$ indicates a subsequent steady rate of respiration in darkness. Extension line $c d$ serves to emphasize rate difference between initial outsurge and subsequent steady respiration rate. The slope of segment ef indicates initial intake rate upon illumination. Slope of segment $f h$ indicates subsequent intake rate. Extension of line $f g$ serves to emphasize the rate difference between initial insurge of and subsequent intake. 
Comparison of cycles at high $\mathrm{CO}_{2}$ concentration with those at lower concentration (fig. 3) suggests that insurge diminished with decreased $\mathrm{CO}_{2}$ concentration, whereas outsurge remained essentially unaltered. The

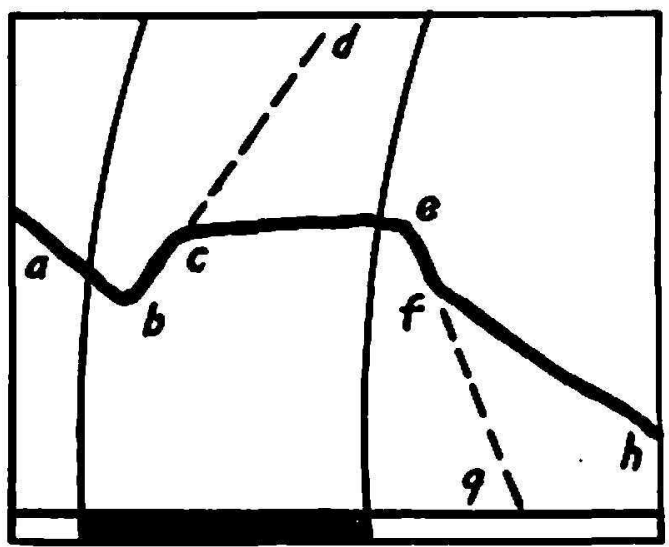

FIG. 4.-Enlarged view of the first light-dark-light cycle (upper left) of fig. 3. Slope of segment $a b$ represent rate of apparent photosynthesis. Slope of segment $b c$, and extension line $c d$, represent initial rate of $\mathrm{CO}_{2}$ evolution following darkening of leaf. Slope of segment ce represents subsequent steady rate of respiration in darkness. Slope of segment $e f$, and extension line $f g$, represent initial rate of $\mathrm{CO}_{2}$ intake following illumination. Slope of segment $f h$ represents subsequent steady rate of $\mathrm{CO}_{2}$ intake, apparent photosynthesis. Angles $d c e$ and $g f h$ represent surge rates in excess of subsequent steady rates.

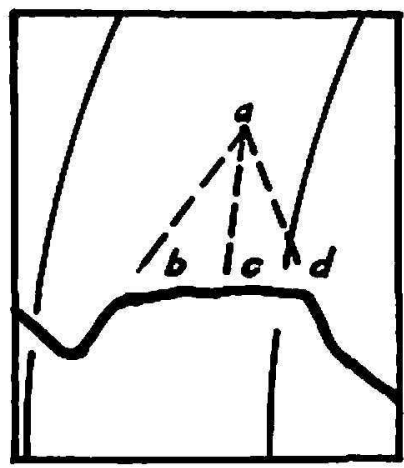

A

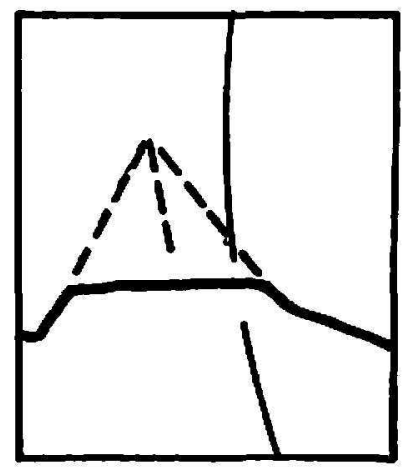

B

Fig. 5.-Enlarged views of the first (A) and fourth (B) cycles of fig. 3. Line $a b$ represent outsurge rate, line ad represents in surge rate, line $a c$ is drawn tangent to an arc of the recorder pen at about the midheight of the two surges. Comparison of angles $b a c$ and cad gives a direct comparison of the relative surge rates.

suggested decrease appears to be largely an instrumental artifact, however. When the curves are corrected for curvature of ordinal axis introduced by rotation of the recorder pen, the differential nearly disappears, as shown in figure 5. The geometrical method of correction is described in the caption of figure 5 . 
A preliminary study was made of effects of light intensity and light quality. Surging decreased with decreased light intensity, but was still clearly discernible at $\mathbf{5 0 0}$ foot-candles. No clear and consistent difference was evident under equal intensities of blue light (deep blue cellophane filter), red light (deep red cellophane filter), and white light. All intensities were measured with a Weston model 756 illumination-meter, with the sensitive cell held horizontally at the position of a leaf.

\section{DISCUSSION}

Decker and Wien (2) showed by other methods that respiration$\mathrm{CO}_{2}$ production-during photosynthesis in eucalyptus leaves was severalfold greater than in darkness. They suggested the following sequence of events to explain the observed surging: A leaf is respiring at the usual rate in darkness; upon illumination photosynthesis begins and accelerates rapidly to a steady rate far in excess of that generally believed; a few seconds later respiration accelerates-photorespiration-and masks photosynthesis back down to normal apparent photosynthesis. Photosynthesis stops quickly when the leaf is suddenly darkened; photorespiration decelerates a few seconds later, but is momentarily exposed as an outsurge. The same explanation is probably applicable to surging in coffee.

It is conceivable that further studies of photosynthetic surging may provide a useful approach to certain problems in plant breeding-for example, those concerned with increasing the dry-weight increment rate or sugar yield of crop plants. Dry-weight increment is directly proportional to the excess of photosynthesis over respiration, and a plant variety showing an unusually high rate of dry-weight increment must have an unusually large excess of photosynthesis over respiration. The results reported in this paper suggest that most photosynthetic work done by leaf is immediately cancelled by photorespiration - with only a relatively minor part remaining as net gain or dry-weight increment. Perhaps there are individuals within a species that have exceptionally high photosynthetic capacity, but this is combined with exceptionally high photorespiration, and the result is normal net gain. Perhaps there are other phenotypically normal individuals that have unusually low photosynthetic capacity combined with unusually low photorespiration. If such individuals could be found, and if the two processes are genetically separable, it may be possible to produce a recombination that includes unusually high photosynthesis and unusually low photorespiration with an extremely high dryweight increment rate. Perhaps this is an explanation for some kinds of observed heterosis. 


\section{SUMMARY}

This paper presents the results of a study in which leaves of coffee plants were submitted to repeated light-dark-light cycles, to observe their effects on respiration and photosynthesis. The results suggest that most of the photosynthetic work done by a leaf is immediately cancelled by photorespiration and, consequently, only a minor part remains as net gain or dry-weight increment.

\section{RESUMEN}

Este estudio presenta los resultados de una investigación para determinar los efectos de ciclos alternados de luz-sombra-luz en la respiración y la función fotosintética de las hojas de café. Los resultados obtenidos sugieren que la mayor parte del producto de la fotosintesis de una hoja es cancelada inmediatamente por la fotorespiración y como consecuencia, una pequeña parte del producto fotosintético permanece como ganancia neta y pasa a ser parte del peso seco de la planta.

\section{LITERATURE CITED}

1. Decker, J. P., and Tí, M. A., Photosynthesis of papaya as affected by leaf mosaic, J. Agr. Univ. P.R. 42 145-50, 1958.

2. Decker, J. P., and Wien, J. D., Carbon dioxide surges in green leaves, $J$. Solar Energy Sci. \& Eng. 2 39-41, 1958.

3. Nutman, F. J., Studies of the physiology of Coffea arabica, I: Photosynthesis of coffee leaves under natural conditions, Ann. Bot. n.s. 1 (3) 353-68, 1937.

4. - Studies of the physiology of Coffea arabica, II: Stomatal movements in relation to photosynthesis under natural conditions, Ann. Bot. n.s. 1 (4) 681-94, 1937. 